\title{
Rich Feature Analysis as an Enabling Tool for Composition Teaching
}

\author{
Ruyun $\mathrm{Hu}$ \\ Chong Qing Normal University, Chong Qing, China
}

\begin{abstract}
Exploring the usage of language in light of its functions in specific pragmatic contexts, Systematic Functional Grammar (SFG) can be a promising tool for language teaching. Relying on this tool, teachers can promote learners' linguistic awareness from the level of passive rule-following to that of explicit understanding, a level where they can see linguistic expression's functional significance as explanation of their effectiveness. This paper is intended as a demonstration of such an explanatory procedure. Employing a SFG-based Rich Feature Analysis to examine students' composition, it aims to show how we can efficiently and convincingly identify and explain some problematic constructions in their writing.
\end{abstract}

Index Terms — rich feature analysis, systematic functional grammar, writing

\section{INTRODUCTION}

Form is explained by function--if the kernel of SFG can be simplified in this way, its potential for language teaching is enormous. As language teachers, we often come across various linguistic features in our students' writing, which, depending largely on an intuitive judgment, are stamped pathological. Yet when facing the question "why such expressions are abnormal?", we found our intuitive knowledge too weak for launching a persuasive explanation. "It's the convention, so just do it!", this kind of answer brings nothing constructive to composition instruction. This gap between observation and explication, between instinctive rule-following and explicit understanding, can be well filled by a SFG-style analysis, for where traditional grammar and prescriptive rules of composition fail, it manages to overcome such problems by relating the textural to the contextual, the formal to the functional, and the abstract convention to the living usage. This is exactly the aim of this current small-scale analysis. Deploying one of the common discourse analysis tools, rich feature analysis, and targeting at four samples of student writing, it sets out to identify those linguistic features differentiating inferior pieces of writing from their superior peers in the academic context; by relating these features to their functional significance, it tries to arrive at a sound and persuasive explanation of their infeasibility. This whole project is also intended as an exemplification of deployment of discourse analysis tools and functional understanding of the difference between written and spoken language to address practical pedagogical problems. But before a full launch into this project, a brief introduction to rich feature analysis is necessary.

Rich feature analysis, our method involved here, is a common discourse analyzing tool combining qualitative and quantitative study. It identifies in a linguistic sample "a rich feature or a set of related rich features; defines the features linguistically by focusing on structure, function, or both; describes the conventional meaning or significance of the feature(s); establishes and verifies the patterns of the feature(s) within a set of texts; and explains how the resulting discourse analysis is interesting for the field of composition theory and pedagogy" (Barton, 2004, p.75). Its target, rich feature(s), are defined as "particular features in a text or a set of texts that are associated with conventions of meaning and significance in context", possessing both "linguistic integrity (i.e., they are structural features of language, so they can be defined in linguistic terms and then categorized, coded, counted, and otherwise analyzed empirically) and contextual value (i.e., they can be conventionally connected to matters of function, meaning, interpretation, and significance)" (ibid). The relation between a rich feature's linguistic form and contextual value is the focus of rich feature analysis.

The object of this study comes naturally behind this belief introduction to the method. It consists of a mini-corpus of pairs of weaker (text A \& B) and stronger (text C \& D) argumentative essays by secondary school students. Text A and $\mathrm{C}$ share the topic of decline in the quality of education, while text $\mathrm{C}$ and $\mathrm{D}$ deforestation. The two weaker texts received impressionistic comments from the teacher such as "write just the way they speak", or "this gives the impression you're chatting with someone instead of writing an essay", while the stronger texts received praise from the teacher like "you show a good command of academic writing". From a personal perspective, such comments possess an affective but not a persuasive value. They impressionistically passed judgments on the quality of the students' writing, but failed to point out the hidden causes waiting to be dug out. As it's been stated at the beginning, this is the gap this study intended to fill.

Following the approach of rich feature analysis and considering local characteristics of the object, the procedures of this study mainly consists of five steps. Firstly, through a detailed examination of the mini-corpus, it identifies three rich features of the weaker sample texts, namely, excessive usage of personal pronouns, misusage of verbal process, and a loose way of information packing (lexical density). Each this identification, it provides a structural definition and 
analysis of the specific rich feature concerned. Then its distributive pattern over the sample texts will be drawn out and a contrast of its distribution between the weaker and the stronger texts will be made. After that, drawing on the literature on spoken and written modes of language and related research on discourse analysis, the identified rich feature's functional significance in the academic writing context will be addressed. At last, the resulted pedagogical implication will be discussed. So far the aims, method, object, procedures of this study has become quite clear, let's proceed from the first rich feature, excessive use of personal pronouns.

\section{EXCESSIVE Use of PERSONAL Pronouns}

The most salient feature shared by the two weaker texts (text A \& B) is the widespread use of personal pronouns. In text A, the use of first-person pronoun "I" and the second-person pronoun "you" is abundant. In text B, the phenomenon is slightly different, with the use of "I" and "you" alleviated a little, but the abundance of the first plural pronoun "we" makes the situation equally serious. To demonstrate this observation, here are some examples from these two weaker texts:

1. I believe, and I am sure most of you do, that the young people today are not getting a fair go with the low educational standards in many schools. (text A, Para. 2)

2. Every day you can see that teachers are not able to keep their students in check, and so their classes become chaotic, and then some students become so disruptive that the others cannot concentrate and have trouble learning. (text A, Para. 2)

3. I think that every child must be taught these skills and when we reach the upper grades we should go further and learn more advanced things. (text A, Para. 3)

4. But if we go ahead and remove trees in more parts of our rainforests we can acquire more usable land. (text B, Para. 2)

5. Think of the many things we can produce from the trees in the rainforest, starting with basic stuff like paper, which we use to write on and it's also necessary for the books we read. (text B, Para. 3)

6. I hope I have convinced you that you should support deforestation, because I am certain that if you do, you will see how much it can benefit our people. (text B, Para. 4)

A brief analysis will help to classify the use of pronouns in the two weaker texts into three groups:

Self mention: the use of first person pronouns and possessive adjectives to make explicit authorial stance. The "I"s in the examples above are mostly of this usage.

Reader engagement: the use of personal pronouns, usually second-person pronouns for involvement of reader. The "you" and some of the "we" above are instances of this usage.

Coalition forming: the affective use of personal pronouns, usually the first plural "we", to bind the writer and reader together, and to send a signal of fellowship by textually constructing both the reader and the reader as participants with similar understanding and goals"(Hyland, 2005, p.182). Most of the "we" above, except for reader engagement, are also of this usage.

Contrasting the distribution of personal pronouns (only $I$, you, we, and $u s$ are counted) in the two weaker texts with that in the two stronger texts, the difference is more than significant. The result is presented in the following chart:

CHART 1

USE OF PRONOUNS

\begin{tabular}{lllll}
\hline & Text A & Text B & Text C & Text D \\
$\mathrm{N}^{1}$ (total number of sentences ) & 11 & 13 & 12 & 14 \\
$\mathrm{~N}^{2}$ (number of sentences with a personal pronoun or more) & 10 & 11 & 0 & 0 \\
Percentage $\mathrm{N}^{1} / \mathrm{N}^{2}$ & $90.9 \%$ & $84.6 \%$ & 0 & 0 \\
\hline
\end{tabular}

The chart above presents the result clear enough. Although the respective number of sentences of the four sample essays are relatively stable, the ratio of sentences with at least one pronoun in the two weaker texts is quite high. In contrast, in the two stronger texts, existence of personal pronouns can hardly be located. It must be added that while counting sentences with pronouns, the related adjective pronouns like my, your, and our are not included for the sake of convenience. If counted in, the ratio concerned could turn out more startling in the two weaker texts.

So much about the statistics, what is the significance of this rich feature? What does its prominence or absence in certain texts mean? Remember at the beginning of the study the teacher's comments on the two weaker texts were mentioned, does this feature, the excessive use of personal pronouns has anything to do with the impression that their authors "write the way they talk" and their writing looks like "they are chatting with someone rather than writing an essay"? This issue can be addressed from the following angles.

Firstly, the use of personal pronouns is related more to a spoken rather than a written mode of speech. The most obvious difference between a spoken and a written mode of texts, as Hammond (1991, p.32) put it, is that "the former are normally jointly constructed by two or more participants, while the latter are essentially monologues". Spoken texts are collaboratively created by interlocutors sharing the same physical context and are organized in a turn-shifting structure. In this linguistic mode, the frequent appealing to the "you" is made possible by the close spatial and temporal distance between the interlocutors, and "you" here is tangible. Also the conversational cooperative, turn-shifting 
structure requires the "I", who's speaking, to frequently go back to the "you", who's both a listener and contributor, to check understanding, engage attention, seek consent, and ask for contribution. In contrast, for a written mode of language, the writer and the reader are both spatially and temporally removed from each other, so the writer "cannot depend on a shared context to convey anything of the meaning", therefore "the meaning must be contained within the text itself" (ibid). In this mode, if the "I", who's writing, constantly appeals to "you", who is absent and often anonymous, this appealing would be empty and only gestural, and excessive use of it may damage the intactness of the written message. Thus Halliday's (2002, p.340) comments: "speech and writing as forms of discourse are typically associated with the two modal points on the continuum from most spontaneous to most self-monitored language, spontaneous discourse is usually spoken, self-monitored is usually written." This said, the relation between the overuse of personal pronouns in the two weaker texts and the teacher's impression of them become obvious.

Secondly, this feature's impertinence also has something to do with the argumentative genre. Any argumentation prescribes a potential dissenting reader, for controversy is its innate motivation. To put it frankly, if there isn't a potentially disapproving reader or listener, there is no need to launch an argument. The potentially dissenting reader could be the most important reader of any argumentative essay. This said, the excessive use of "we" in the weaker texts seems rather imposing. As Hyland (2005, p.182) puts it, the use of "we" sends a clear signal of membership by textually constructing both the writer and the reader as participants with similar understanding and goals". With the widespread use of "we", the potential dissenting reader's reluctance to hastily join the ally before being soundly persuaded is trampled overhead. The same can largely said of the excessive use of "you".

Finally, for an argumentative essay, the over use of "I" will weaken its persuasive power. As it is said before, an argument presupposes difference of opinions, so there comes the need to demonstrate a certain opinion's soundness. This demonstration, for an optimal consideration, should follow a reasonable procedure for both sides, and draw on evidence and facts objective for both sides. Frequent turning back to one's own subjective perspective is not constructive for resolving the controversy at issue. The frequent use of "I" just gives the speaker's argument a subjective hue. If every evidence, every step of reasoning is contained inside a subjective frame, how can its objectivity be recognized? To write in this way is more of an exchange of personal ideas rather than persuasion. This may explain the teacher's comment that the authors of the weaker texts seem like chatting with someone rather that writing an essay.

\section{Misuse of Verbal PROCESS}

The second rich feature surfaces first as a general impression: in the two weaker texts, there are too many "I think...", "I believe..."; and there are a lot of happenings there but rarely any relation between such happenings. As to the pervasive presence of "I think..." and "I believe...", the following paragraph from Text A suffices as a superb example:

I believe, and I am sure most of you do, that the young people today are not getting a fair go with the low educational standards in many schools. In my school I have noticed that there is a big problem with discipline. Every day you can see that teachers are not able to keep their students in check, and so their classes become chaotic, and then some students become so disruptive that the others cannot concentrate and have trouble learning.

As for the phenomenon of too many things happening but scarcely any reasoning, the following paragraph from Text B helps to make the case:

First of all we need to consider that our rainforests take up a huge area of our country, and all this space cannot be utilized in order to benefit our people. But if we go ahead and remove trees in more parts of our rainforests we can acquire more usable land. Once we get more land, farmers can grow crops to provide us food and medicines, and the land can also be used to provide housing. The trees of the rainforests give us building material and at the same time as the trees are cut down, the land gives us the area for houses. We have to build more houses because our population is growing fast as more and more migrants come into our country.

Deploying Halliday's transitivity theory to a brief analysis of the main clauses from these two short samples will easily reveal why they tend to give us such an impression.

CHART 2:

TRANSITIVITY ANALYSIS OF TEXT SAMPLE FROM TEXT A

\begin{tabular}{llll}
\hline \multicolumn{2}{c}{ TRANSITIVITY ANALYSIS OF TEXT SAMPLE FROM TEXT A } & Process(es) involved \\
Participant(s) & Verb(s) & Other participant(s) & mental \\
I & Believe, be sure & clause & mental \\
I & notice & clause & mental \\
you & see & clause & \\
\hline
\end{tabular}

CHART 3:

TRANSITIVITY ANALYSIS OF TEXT SAMPLE FROM TEXT B

\begin{tabular}{llll}
\hline Participant $(\mathrm{s})$ & Verb(s) & Other participant(s) & Process(es) involved \\
\hline we & consider & clause & mental \\
\hline we & can acquire & more land & material \\
\hline farmers & can grow & crops & material \\
\hline The land & can be used & & material \\
\hline The trees of the forests & give & us, Building material & material \\
\hline The land & give & us, building materials & material \\
\hline we & have to build & more houses & material \\
\hline
\end{tabular}


The results presented above demonstrate that the initial impression triggered by these two texts is not of an accidental nature. In the sample from Text A, all the main clauses involve a mental process. As it is well known, mental processes are mainly processes of sensing or perceiving, which "may be construed as either flowing from a person's consciousness or impinging on it", and "the person who does the thinking, feeling, or perceiving is the experiencer and what is thought, felt, wanted, or perceived is the phenomenon (or experience)"(Coffin et al., 2009, p.303). The mental process inevitably gives what is perceived or sensed a subjective hue, thus a text's excessive reliance upon this process for its structuring naturally appears less objective, or, in the case of an augment, less persuasive.

With the case of material process, it brings in more "going-on", as "the presence of material clauses means that people or things are "doers" (i.e. agents): they act and do and, as a consequence; there are changes: the emerging account feels more dynamic" (ibid, p.295). Therefore, the world represented through a material process appears more of a world in process, a world of happening. This type of process is usually associated with the spoken mode of language, as "written language represents phenomenon as if they were products", while "spoken language represents phenomenon as if they were process" (Halliday, 2002, p.344). This said, a text reliant too heavily on material process will give its reader a sense of its being spoken rather than written. This is also what the teacher's comment over the two weaker texts implied. However, this doesn't mean material process has no place in the written mode. In some genres which focusing on an account of happenings, actions, or motions around the world, it naturally become the recommended choice. Of such genres, narrative is a superb representative. For argumentative writing, whose focus should be on reasoning about the happenings instead of the happenings themselves, over reliance on the material process for its development normally seems impertinent.

Does this mean the material process is absolutely poisonous for an argument? The answer is still no. Properly used, it can actually enhance an argumentative writing's reasoning power. A transitivity analysis of some sentences from one of the stronger texts in our little corpus will serve as a good demonstration:

CHART 4:

TRANSITIVITY ANALYSIS OF SENTENCES FROM TEXT C

\begin{tabular}{llll}
\hline Participant(s) & Verb(s) & Other participant(s) & $\begin{array}{l}\text { Process(es) } \\
\text { involved }\end{array}$ \\
\hline $\begin{array}{l}\text { Combined classes and honours } \\
\text { programmes }\end{array}$ & allow & gifted students the opportunity to... & material \\
\hline $\begin{array}{l}\text { This (learning support programmes } \\
\text { giving students with learning } \\
\text { difficulties extra encouragement })\end{array}$ & has not only led to & $\begin{array}{l}\text { better exam results, but also an increase } \\
\text { in the capabilities }\end{array}$ & material \\
\hline $\begin{array}{l}\text { The abolishment of the practice of } \\
\text { canning... }\end{array}$ & $\begin{array}{l}\text { has not brought } \\
\text { about }\end{array}$ & a dramatic fall in standards of discipline & material \\
\hline
\end{tabular}

The three sentences from text $\mathrm{C}$ shares the same kind of process with those earlier analyzed sentences from text A \& $\mathrm{B}$, a material process. The key difference lies in the participants involved. Here the active participants are not real human or thing in the world, but nominal constructions representing state of affairs. They are more of concepts abstracted from, therefore elevated above, real things in the world. As a result, the action verbs following them are not actually used to represent real, material process of happening or action, but to reveal the logical, causal relations between states of affaires. Their function is more like that of conjunctional devices. For instance, if translated into a more spoken version with the causal relation between its participants explicitly expressed, the first sentence could turn into this:

There are combined classes and honor programs, and because of this, the gifted students get their opportunity to realize their full potentials.

In this version, not only the sentence become much longer, but as its grammatical complexity increased, and some explicit conjunctional devices representing causal relation are also needed. Comparing these two versions, one can instantly observe the causal relation is intact in both cases, but the first version is more concise and condensed. This is typical for both the writing mode of language in general and writing in the academic context, for, as Schleppegrell (2004, p.64) put it, “...the way logical relationships are indicated differs between interactional and school-based registers, as school-based texts less use explicit conjunctive links and more often incorporate the logical relation in nominal or verbal elements". Reasoning with verbs also reminds one of the phenomenon of "grammatical metaphor", where "one kind of process has been dressed up by the grammar to look like a process of a different kind" (Halliday, 2002, p.346). Written language, Halliday (ibid, p.347) comments, "tends to display a high degree of grammatical metaphor, and this is perhaps its single most important characteristic".

To sum up, the two weaker texts displays incompetence in verbal process deployment; their texts contains too much use of the mental process and material process. Because of the former, their texts sound more subjective and spoken-like; because of the latter, more dynamic and more narrative-like.

\section{LEXICAL DENSITY}

Comparing the two weaker texts with the other two, a third rich feature comes up. It also comes first as a general impression: what the stronger texts can express in a single word will cost the weaker texts a sentence; what the stronger 
texts can express in a simple sentence, it will cost the weaker texts a fat one with clusters of clauses. SFG possesses a specific term for the description or measurement of such density or looseness of information in a text: lexical density.

Lexical density is "the proportion of lexical items (content words) to the total discourse" (Halliday, 2002, p.329). It is measured in various ways, of which one of the most widely adopted is the number of lexical items (relative frequency ignored) as a proportion of the number of clauses (embedded clauses ignored) (ibid). As stated above, the two weaker texts give one the impression of its looseness of information-packing, so hopefully an analysis of the lexical density of two pieces of sample from them may help to reveal the hidden reason:

Also many of us can't even read, write or do math properly,// which leaves us with poor exam marks./// I think// that every child must be taught these skills// and when we reach the upper grades// we should go further// and learn more advanced things.../// (from text A, Para. 3)

First of all we need to consider// that our rainforests take up a huge area of our country,// and all this space cannot be utilized// in order to benefit our people./// But if we go ahead// and remove trees in more parts of our rainforests// we can acquire more usable land.../// (from text B, Para. 2)

Clause complex boundary ///

Clause boundary //

Embed clause

Lexical items show in boldface

CHART 5:

RESULTS OF LEXICAL DENSITY ANALYSIS (SAMPLES FROM TEXT A \& B)

\begin{tabular}{lllcl}
\hline & Lexical items & Clauses & Running words & Lexical density \\
\hline Sample/text A & 20 & 7 & 45 & 2.9 \\
Sample/text B & 19 & 7 & 51 & 2.7 \\
\hline
\end{tabular}

The analyzed samples from the two weaker texts are of approximately the same length, and their lexical densities are also close to each other, with both slightly below 3. To get a better sense of the significance of the results, it's better to do a similar lexical density analysis of language samples from the two stronger texts and make a contrast:

Furthermore, despite much argument to the contrary, the abolishment of the practice of caning in schools has not brought about a dramatic fall in standards of discipline./// Punitive measures like detention and internal suspension are more than enough to stop most problem students.../// (from Text C, Para.3)

In addition to the provision of greater opportunities for work, the removal of trees in some parts of the rainforests could also assist in the securing of land for farming and housing in cost-effective ways./// Housing provides the necessary homes for a steadily and rapidly increasing population .../// (from Text D, Para. 2)

CHART 6:

RESULTS OF LEXICAL DENSITY ANALYSIS (SAMPLES FROM TEXT C \& D)

\begin{tabular}{lllll}
\hline & Lexical items & Clauses & Running words & Lexical density \\
\hline Sample/text C & 20 & 2 & 43 & 10 \\
Sample/text D & 23 & 2 & 47 & 11.5 \\
\hline
\end{tabular}

Comparing the results of the two analyses, one can instantly observe the significant difference. The lexical density of the samples from the two stronger texts is approximately 3-4 times that of the samples from the two weaker texts. The statistics clearly demonstrate that information in the two stronger texts is more densely packed. Higher lexical density is conventionally a property of the written mode of language, as Halliday (2002, p.329) put it, "since written language is characteristically reflective rather than active, in a written text the lexical density tends to be higher; and it increases as the text becomes further away from spontaneous speech". Thus the lower lexical density of the two weaker texts serves as another proof to support the teacher's initial comments.

However, if analysis of this feature in the students' essays ends at this point, it will serve little practical purpose. Even if the students know the significance of lexical density in the academic writing context, without understanding where they are from, the possibility of improvement is still only in the air. A further research into the high lexical density of the two stronger texts reveals that it mainly a result of one important textual feature termed by Halliday (2002, p.345) as grammatical metaphor. It influences a text's lexical density at two levels at the same time. On the syntactic level, it enables verbal, nominal, and prepositional elements to represent logical relations, thus reduces the number of clauses and conjunctional structures. This issue has been addressed in the previous part dealing with verbal process, but another example would do no harm. Here is a sentence from the sample D analyzed above:

a)...the removal of trees in some parts of the rainforests could also assist in the securing of land for farming and housing in cost-effective ways.

Here assist in is actually representing a causal relation. If we rewrite it using conjunction words, as it is usually done in spoken, informal language, its structure would become much more complicated involving a complex sentence with two subordinate clauses:

b) Because trees in some parts of the rainforests are removed, land for farming and housing is secured in cost-effective ways.

Using one grammatical form to accomplish the same function of another for the sake of economy and effectiveness 
of expression, this is typical of grammatical metaphor. In the example above, an action verb is used to do the job of expressing a causal relation, which is usually accomplished through using clauses in conjunction. Although in this way reliance upon syntactic structure for information packing is alleviated, more work is demanded of the lexical items. To avoid loss of information, it has to be packed into the lexical level. Here grammatical metaphor again plays a major role. Nominalization is a typical instance. In the above example, what is expressed in the latter version through two clauses is packed in the first version into two nominal groups, taking up places traditionally called subject and object. Through such analysis, we can see grammatical metaphor as one of the hidden sources of a text's higher lexical density, the ultimate motivation of which is perhaps written language's need of dense information packing.

\section{Pedagogical IMPlication}

The analysis above of four students' texts has demonstrated our analytical method's promising potential for composition instruction. This potential can be approached from two directions.

Firstly, for teachers, rich feature analysis and related SFG analytical resources will help them get an in-depth, rational grasping of the problems in their students' writing. As teachers, when we pass our judgments onto our students' writing, those comments tend to be impressionistic. There certain language features are diagnosed as pathological, but the reason why they appear so is often hard to explain. Our own competence and familiarity enable us an instinctive haunch to hunt down those features making a certain piece of writing good or bad. But the point of composition instruction is not making such judgments even if they are accurate, for if it were so, then composition instruction would turn out to be a form of testing instead of teaching writing. To develop learners' competence, teachers not only must know what their problems are, but also how such problems come forth. The pathological symptoms must be traced to their sources, only then can a cure be developed. Rich feature analysis, starting from surface language features, proceeding to define them in linguistic terms, verifying their pattern across texts, and seeking their significance in contexts, is a handy tool for teachers to rationally diagnose such problems. In case of our study above, through the lens of rich feature analysis, the impression triggered by the weaker texts, that they sounds like their authors are chatting with somebody, actually points to the students' unfamiliarity with the writing mode of language and the argument genre.

Secondly, for students, this kind of analysis will help them to identify the essential causes for their writing's weakness, thus enable them to know at least where to start for improvement. Impressionistic comments like "you write as you speak" will not get them far on the path to competent writers. More likely, it will only bring in negative effects like discouragement and loss of motivation. Reasoning with analytic tool like rich feature analysis will convincingly demonstrate to them certain language use's pertinence or impertinence in certain contexts. It will also demonstrate to them that composition is not a matter of following sets of prescriptive rules, but a matter of efficient language use in contexts. For instance, as it is mentioned in our analysis, the use of pronouns is often associated with the spoken mode of language, and they serve tangible purpose there enabled by the close temporal and spatial distance between interlocutors. Knowledge of this kind will enable them to realize what they are learning is not blind following of rules prescribed by some unknown authority, but rules of real world communication. This will boost their motivation.

\section{CONCLUSION}

In this study, we employed rich feature analysis to look into four pieces of student composition, and three rich features of these texts were focused on: the use of pronouns, verbal processes, and lexical density. Starting from close-reading of these texts, the study then set out to identify the three features, define them in linguistic terms, verify their distributive pattern across texts, and reveal their conventional significance in contexts. Through such a process, a rational ground for comments on these texts was established, and an in-depth diagnosis of the weaker texts' problems was accomplished. Results show the problems faced by the weak students are mainly their unfamiliarity with the difference between written and spoken modes of language. Apart from that, their lack of understanding of the argumentative genre is also an important cause. Through this study, we can see rich feature analysis' promising potential in assisting teaching and learning composition. In the near future, we hope to see this methods' pedagogical application further explored.

\section{ApPEndix. Mini-Corpus of Pairs of WeAker (Texts A \& B) AND Stronger Argumentative Essays (TeXts C \& D)} BY SECONDARY SCHOOL STUDENTS

\section{Text A Has there been a decline in the quality of education?}

1. As you know, people have recently been writing in the newspapers about the standards of current school leavers. I support all those writers who have been arguing that we young people do less well academically, because as a student myself I can see it happening.

2. I believe, and I am sure most of you do, that the young people today are not getting a fair go with the low educational standards in many schools. In my school I have noticed that there is a big problem with discipline. Every day you can see that teachers are not able to keep their students in check, and so their classes become chaotic, and then some students become so disruptive that the others cannot concentrate and have trouble learning.

3. Also many of us can't even read, write or do math properly, which leaves us with poor exam marks. I think that 
every child must be taught these skills and when we reach the upper grades we should go further and learn more advanced things. But this is not happening, and what makes it worse is that our teachers are not held accountable, and they are also often blind to the fact that the number of illiterate people in our country is rising.

4. To all the parents out there, I'd like to say that we cannot afford to ignore this problem but must grasp it and face it head-on so that the situation in our schools will be fixed. I am one of the students affected, and so are most of my classmates, and I urge you to do something about it. Let us defend the educational standards of our young people, look into the aspects I have mentioned and make sure that things will be better in the future.

\section{Text $B$ In support of deforestation}

1. Currently a lot of people are debating whether or not we should remove trees from our rainforests. I am going to discuss why I believe that those in favour of deforestation make the stronger case and that theirs is the better way for us to go.

2. First of all we need to consider that our rainforests take up a huge area of our country, and all this space cannot be utilized in order to benefit our people. But if we go ahead and remove trees in more parts of our rainforests we can acquire more usable land. Once we get more land, farmers can grow crops to provide us food and medicines, and the land can also be used to provide housing. The trees of the rainforests give us building material and at the same time as the trees are cut down, the land gives us the area for houses. We have to build more houses because our population is growing fast as more and more migrants come into our country.

3. Deforestation can also boost our economy. Think of the many things we can produce from the trees in the rainforest, starting with basic stuff like paper, which we use to write on and it's also necessary for the books we read. And deforestation supports our economy in other ways because we don't just use all those products from the rainforests ourselves but we sell them to other countries. Also let's not forget that the trees are cut down by loggers. These people would be out of a job if there was no deforestation, and so they wouldn't be able to support their families, plus many of the small towns in which they live would suffer and maybe even vanish.

4. I hope I have convinced you that you should support deforestation, because I am certain that if you do, you will see how much it can benefit our people.

\section{Text C Has there been a decline in the quality of education?}

1. There has been an ongoing debate in the local press about the standard of current school leavers, with especially employers insisting that young people who leave school today have a lower level of educational achievement than in the past. However, this issue is highly complex and must be considered from various angles.

2. Most schools today are more concerned with academic achievement and the provision of a range of course choices than ever before. In this day and age many educational pathways are open for students of different interests, background and capabilities. On the one hand, combined classes and honours programmes allow gifted students the opportunity to realize their full potential. On the other hand, there are learning support programmes which give students with learning difficulties the extra encouragement that they need to reach the next level of their education. This has not only led to better exam results, but also to an increase in the capabilities students have in the areas of reading, writing and mathematics.

3. Furthermore, despite much argument to the contrary, the abolishment of the practice of caning in schools has not brought about a dramatic fall in standards of discipline. Punitive measures like detention and internal suspension are more than enough to stop most problem students. If one adds to these measures incentives like enrichment programmes for students that have behaved to an acceptable standard to this, the problems with discipline can be quite readily solved.

4. While the standard of some current school leavers may be low, the majority of students succeed in completing their academic studies with a higher level of educational achievement than in the past. Looking at the issue objectively, the quality of education received and the standard of achievement are not dropping; they are equal or even superior to those of the past.

\section{Text D Deforestation: Yes or No?}

1. In recent years there has been a great deal of debate in Australia over whether rainforests should be logged. While conservationists argue for the protection of the rainforests as habitats for valuable plants and wildlife, the logging industry has made a case in favour of strategic deforestation. A closer examination of the arguments of the proponents of the two sides reveals that the issues at stake are by no means straightforward.

2. To put their main arguments in a nutshell, those in the logging industry contend that it is necessary for some rainforest areas to be removed because of the employment opportunities which their removal can create and the economy which can be sustained as a result. In addition to the provision of greater opportunities for work, the removal of trees in some parts of the rainforests could also assist in the securing of land for farming and housing in cost-effective ways. Housing provides the necessary homes for a steadily and rapidly increasing population, and farming can supply a wide range of products that are required for everyday living, such as meat, milk, vegetables and wool. These are all vital necessities for Australia's continuing economic development and the improvement of the standard of living of its population.

3. Those who insist on phasing out the practice of logging offer as their most important argument its destructive impact on the environment. According to these conservationists, logging affects the rainforest ecosystem in a number of 
ways. First, the clearing of rainforest means the loss of large quantities of unique plant and animal species. Despite their diminishing area, the rainforests of Australia still retain the greatest number of flowering plant species in the world. Extinction of these plant species will result in radically altered ecosystems which are unable to recover easily from environmental stress. Secondly, logging operations have contributed to the extinction of many animals directly and indirectly through the destruction of their habitats. Thirdly, logging has also been shown to increase the level of environmental pollution.....

\section{REFERENCES}

[1] Barton, E. (2004). Linguistic discourse analysis: How the language in text works. In C. Bazerman \& P. Prior, (eds.), What writing does and how it does it (pp.57-83). Mahwah, N. J.: Lawrence.

[2] Coffin, C., Donohue, J. \& North, S. (2009). Representing the world. In exploring English grammar (pp.282-309). London: Routledge.

[3] Halliday, M. A. K. (2002). Spoken and written modes of meaning. In J. Webster (ed.), On Grammar, Vol. 1 of Collected works of M. A. K. Halliday (pp.323-351). London: Continuum.

[4] Hammond, J. (1991). Is learning to read and write the same as learning to speak? In F. Christie, (ed.), literacy in a changing world. Hawthorn, Victoria: ACER.

[5] Hyland, K. (2005). Stance and engagement: a model of interaction in written discourse. Discourse studies (pp.26-53) 7(2), 173-192.

[6] Schleppegrell, M. (2004). Linguistic features of academic registers. In The language of schooling (pp.43-76). Mahwah, N. J.: Lawrence Erlbaum.

Ruyun Hu, graduated from the University of Nottingham in UK, now is the lecturer of English Department at Chong Qing Normal University in China. Her current interests include learner autonomy, methodological and theoretical challenges in the investigation of cross-linguistic influence. 